\title{
COMPARING THE EFFECTS OF INTRANASAL BETAMETHASONE SODIUM SULPHATE AND BECLOMETHASONE DIPROPIONATE IN PATIENTS WITH ALLERGIC RHINITIS
}

\author{
Amir Ali Khan, Tehmina Rehman Syed, Attique Ahmed, Usman Rafique \\ Combined Military Hospital Bahawalpur/National University of Medical Sciences (NUMS) Pakistan
}

\begin{abstract}
Objective: To compare the effects of Intranasal Betamethasone and Beclomethasone in patients with Allergic Rhinitis. Study Design: Quasi experimental study.

Place and Duration of Study: Combined Military Hospital Bahawalpur and Shahida Islam Medical and Dental College Lodhran, from Mar 2018 to Feb 2019.

Methodology: A total of 200 patients who were between 22-55 years of age were included in this study. Half of them received Intranasal Betamethasone were compared with the other half who received Intranasal Beclomethasone. Clinical success was compared in both groups in terms of patients becoming a symptomatic.

Results: Clinical symptoms were markedly reduced in both groups at the end of the study as 94 (94\%) and 78 (78\%) of patients who were on Intranasal Betamethasone and Intranasal Beclomethasone respectively showing that Intranasal Betamethasone is superior to Intranasal Beclomethasone in controlling Allergic Rhinitis symptoms. Chi square test is applied and $p$-value calculated $(p=0.045)$ significant.

Conclusion: Intranasal Betamethasone is far more effective drug as compare to Intranasal Beclomethasone in controlling allergic symptoms.
\end{abstract}

Keywords: Allergic rhinitis, Betamethasone, Rhinorrhea.

This is an Open Access article distributed under the terms of the Creative Commons Attribution License (https://creativecommons.org/licenses/by-nc/4.0/), which permits unrestricted use, distribution, and reproduction in any medium, provided the original work is properly cited.

\section{INTRODUCTION}

Rhinitis means a presence of two or more of these nasal symptoms i.e. Nasal irritation, watery nasal discharge, nasal blockadeand excessive sneezing. It is one of the world health issues and its prevalence is at an increase, currently $10-30 \%$ of adults and $40 \%$ of children are affected. Rhinitis results from inflammatory exposure of nasal mucosa to allergen. Symptoms of allergic rhinitis result in difficulty in daily routine i.e.: sleep disturbance, fatigue, depression, decreased learning skills and impair quality of life and working performance. The treatment of nasal allergy includes controlling exposure to allergens, drug therapy, and allergen immunotherapy. Intranasal corticosteroids in the form of sprays and drops are the most effective way of treating nasal allergies and their impacts are important in patient compliance ${ }^{1,2}$.

Genetic factor like in other allergic diseases has an important role in nasal allergic rhinitis. A positive family history of allergy is a well-known risk factor for allergic rhinitis. Allergic rhinitis is directly proportional to an increase risk of developing asthma ${ }^{2}$. Different genes are responsible for causing allergic symptoms i.e. a part of the chromosome $5 q$, where genes subsist for interleukin IL-4 / IL-13 associated with increased

Correspondence: Dr Amir Ali Khan, ENT Department, Combined Military Hospital Bahawalpur Pakistan

Received: 08 May 2019; revised received: 20 Feb 2020; accepted: 28 Feb 2020 serum IgE levels. Different loci present on chromosome 11q, chromosome $12 \mathrm{q}$ and chromosome 13 are also seemed responsible ${ }^{3}$. Many risk factors include air pollution like dust and smoke, exposure to animalsfur, pollen grains of flowers of the trees and grasses, mould spores, debris from insects or house mites and house dust are the main allergens. Food allergy is an important but rare cause. The pathogenesis of allergic symptoms also include different cells, mediators, cytokines, neuropeptides, chemokines and bonding molecules reacting in so many ways causing allergy. Specific IgE antibodies are produced by the inhaled allergens in the genetically susceptible individuals. These then become attached to the blood basophils or to the FC end of tissue mast cells. On ensuing exposure, antigen bonds with Fab end of IgE antibody leading to degranulation in the mast cells and set free/liberate several chemical mediators in preformed state while others are newly synthesized capable of causing vasodilation, mucosal oedema, infiltration with eosinophils, and an increased discharge of secretion from nasal glands and contraction of smooth muscle.

Symptomatology of nasal allergy include recurrent sneezing, 10-20 sneezes in one go, blockade of the nose, discharge from the noseusually watery in consistency and irritation and itching in the nose all due to high levels of the chemicals such as histamine, prostaglandin D2 and leukotriene C4 in the nasal mucosa. 
This response is of limited time duration. Late phase response includes symptoms of nasal stuffiness and increased nasal reactivity which is due to permeation of eosinophils, mast cells, macrophages, basophils, neutrophils and $\mathrm{T}$ lymphocytes into the nasal mucous membrane. On examination of nasal mucosa it looks pale and boggy edematous bluish in colour. Nasal turbinates are flabby. Flimsy watery or sometimes thick nasal discharge is appreciated. The tympanic membranes are often retracted because of eustachian tube blockage resulting in serous otitis media. There may be congestionin the oropharynx and post nasal drip ${ }^{5}$.

Diagnosis is based on history (how persistent, frequent, severe, long lasting, intermittent or seasonal the symptoms are), nasal examination and lastly the Skin prick test (Allergen injected into the skin results in release of IgE-sensitized mast cells and chemical substances causing wheal and flare formation ${ }^{6}$. This test is simple cheap and reliable) or radio alle-rgosorbent test (RAST) for specific IgE (finds allergen specific IgE in the blood, it includes allergen fastened to a solid stage, which is brooded with the patient's serum and IgE molecules attach with the allergen. After thorough cleaning, radio labelled anti-IgE estimates specific IgE antibody concentration in the serum of the patient) ${ }^{7}$.

Similarly in the ELISA test the allergen is in the fluid phase and the IgE is enzyme-labeled. The substrate for the enzyme is added and photometrically colour change is detected ${ }^{8}$.

Untreated Allergic rhinitis may often leads to repeated sinusitis because of blockade of the sinus openings, formation of nasal polyps, development of secretory otitis media, orthodontic problems and other adverse-effects of prolonged mouth breathing mostly in children. Patients of allergic rhinitis have four folds higher risk of developing allergic asthma9 .

Management of allergic rhinitis is divided into three main components: Avoidance of allergen, Drug therapy and Immunotherapy ${ }^{10}$. Avoiding exposure to allergen is most recommended if one is allergic to single antigen. Pet removal from living areas, encasing the pillow or mattress in plastic sheet, replacement of work place, job substitution are also suggested. Elimination of a particular allergy causing food item from the diet. Drugs which are in use are antihistamines, alpha adrenergics causing vasoconstriction help reduce nasal congestion and oedema. In addition a large variety of intranasal steroids such as beclome-thasone dipropionate, budesonide, betamethasone, fluticasone, flunisolide acetate and mometasone are usually prescribed. These all causes restrainen listing of the inflammatory cells and suppress latephase allergic reaction thus very effectively control the sym-ptoms. Topical steroids have less systemic side effects but their persistent use may cause nasal mucosalatro-phy, perforation in nasal septum and chances of fungal infestation in the nose and nasal sinuses. There should be a break of 1-2 weeks in the use of intranasal steroids after every 2-3 months of treatment in order to avoid the above mentioned complications ${ }^{15}$.

\section{METHODOLOGY}

This quasi experimental study was carried out in Combined Military Hospital Bahawalpur and Shahida Islam Medical and Dental College Lodhran from March 2018 to February 2019. Two hundred patients were included in the study. Inclusion criterion was age between 22 and 55 years, both genders and patients who had more than 12 weeks history of sneezing, nasal itching, rhinorrhea and nasal obstruction. Exclusion criterion, those patients who were having associated deviated nasal septum were excluded. They were divided into two groups. Group " $\mathrm{A}$ " comprising of 100 patients who were given Betamethasone sodium phosphate $0.1 \%$ nasal drops 2 drops thrice daily in lying and head suspended out of the couch in an extended position along with antihistamine once daily dose. While group " $\mathrm{B}$ " with same number of patients were given Beclomethasone dipropionate nasal spray $320 \mathrm{mcg}$ per day is given as 2 actuations in each nostril (80 mcg nasal aerosols) in an upright sitting position along with same antihistamine. The patients were examined on fortnightly basis for one month.

All the four cardinal symptoms of allergic rhinitis that are sneezing, rhinorrhea, nasal itching and nasal obstruction were closely monitored and those patient who showed remission of all the four above mentioned symptoms were labeled as excellent respondents.

\section{RESULTS}

A total of 200 patients were included in this study. One hundred in group " $A$ " and similarly one hundred in group " $B$ ". In group " $A$ " 90 (90\%) showed excellent response, their symptoms were markedly reduced when reviewed after 2 weeks while $10(10 \%)$ patients continued to have rhinorrhea and nasal itching. The entire group " $A$ " patients were kept on the same drugs and reviewed after another two weeks, 4 out of the remaining 10 patients showed good response but in 6 patients the symptoms persisted (table).

In group "B", 70 (70\%) showed excellent response and markedly reduction in their symptoms at the end 
of second week while $30(30 \%)$ patients continued to have rhinorrhea, sneezing and nasal itching. On review of these remaining 30 patients after another two weeks with the same treatment, 8 showed decrease in the severity of their symptom. But in 22 patients the symptoms persisted.

Table: Summary of patients clinical response after 2 weeks and after 4 weeks.

\begin{tabular}{l|c|c}
\hline Group & Second Week & Fourth Week \\
\hline Group "A" n (\%) & $90(90 \%)$ & $4(40 \%)$ \\
\hline Group "B" n (\%) & $70(70 \%)$ & $8(50 \%)$ \\
\hline
\end{tabular}

So overall $6(6 \%)$ patients of this group " $\mathrm{A}$ " and $22(22 \%)$ patients of group " $B$ " persisted with the disease and they were advised oral prednisolone for 15 days to control their symptoms. Symptoms were markedly reduced in both groups at the end of the study as $94 \%$ and $78 \%$ respectively. So it can be concluded that response of the patients in group " $\mathrm{A}$ " is better than group "B" (figure).

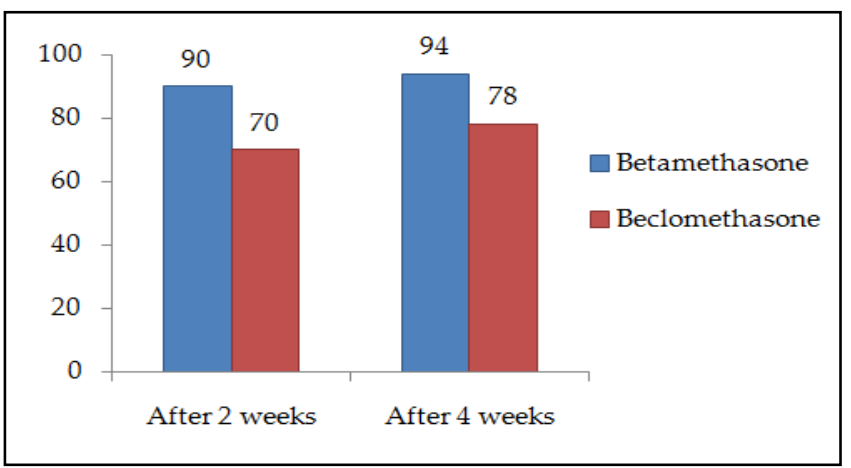

Figure: Results of betamethasone and beclomethasone dipropionate after 2 weeks and 4 weeks.

\section{DISCUSSION}

Traditional classification of allergic rhinitis included Seasonal Allergic Rhinitis (SAR) and Perennial Allergic Rhinitis (PAR) ${ }^{16}$. SAR is an allergic inflammation of the nasal mucosa and upper airways tract that is occurring due to the influence of different allergens like pollens grains of flowers of trees, grasses and wild plants in a sensitized population. While PAR occurs due to persistent impact of allergens like to house dust mites, flaky scales of animal skin, and different other allergens mostly present in one's surroundings. In both types there are four cardinal symptoms thin watery secretion from the nose, congestion/blockade of the nose, sneezing (in series) and nasal irritation/ itching. In addition some people have symptoms of allergy in the eyes, such as itching of eyes and watering of eyes. Inmodern days, allergic rhinitisis classi- fied into the following four types depending on the intensity and time period of the symptoms ${ }^{17,18}$.

- Mild intermittent.

- Mild persistent.

- Moderate/severe intermittent.

- Moderate/severe persistent.

Intranasal corticosteroids are the first-line treatment modality for moderate to severe allergic rhinitis and reduce sneezing, rhinorrhea, post-nasal drip, itching, and nasal blockage and total nasal symptom scores better than antihistamines. Intranasal betamethasone is an effective drug in the treatment of allergic rhinitis. But in patients who have persistent symptoms, giving oral corticosteroid provides additional benefits. Short courses of oral corticosteroid (5-7 days) are helpful in cases not responding to other treatment options. Adverse local effects of intranasal corticosteroids may include pollens bleeding from nose, stinging, burning, and dryness.

Betamethasone is a drug of the corticosteroid group; it is in use since the early 1960s. Despite of other glucocorticoids and non-steroidal anti-inflammatory drugs, betamethasone is still in use in the treatment of several diseases because it is potent, effective and safe. Its potency is 300 times more than hydrocortisone. Its mechanism of action is by activation of a group of proteins known as lipocortins, which in turn inhibit phospholipase A2, responsible for the synthesis of leukotrienes from arachidonic acid, thus blocking the inflammatory cascade. In addition betamethasone also acts directly on leukocytes and inhibit the release of a numbers of chemical mediators such as acid hydrolases and interleukins (Leukocyte acid hydrolases are a potent chemical mediator that recruits white blood cells at the site of inflammation). By inhibiting the liberation of these chemicals, betamethasone prevents the accumulation of macrophages in the area and reduces the adhesion of leukocytes to the capillary wall. Thus reducing the capillary permeability and therefore decreasing the inflammation ${ }^{19}$.

Dowson et al in their study, concluded that daily lavage of nose with betamethasone is an effective way and a reasonable and harmless treatment choice. Suh et al in their study, revealed that Betamethasone nasal drops reduce mucosal inflammation, helps in controlling infection, and restoring mucociliary clearance within the sinuses ${ }^{20}$.

Jonathan Brostoffin his articlereported that betamethasone nasal drops if given in a daily dose of 0.28 
$\mathrm{mg}$, there is no adrenal suppression. He also noted a high rate of symptomatic relief thus suggesting that betamethasone is very potent drug for managing allergic rhinitis ${ }^{21}$. On the other hand in a study conducted by Edward TB, the authorstressed on the point that in comparison with other corticosteroids which caused adrenal suppression and different systemic side effects, beclomethasone dipropionate, remains at the site of application, quickly metabolized, have reduced irritation to the mucosa of the nose, and has a longer duration of action. It thus relieves the patient from sneezing, nasal obstruction and rhinorrhea of seasonal and perennial allergic rhinitis therefore it is safe and effective ${ }^{22}$. Brown et al in their five years review of articles said that Beclomethasone dipropionate is of appreciable therapeutic worth in nasal allergies of all types of prolonged duration ${ }^{23}$.

The results of our research showed that Betamethasone is far superior drug then other intranasal corticosteroids. It brings improvements in the allergic and nonallergic rhinitis as well as nasal polyposis formation and chronic rhinosinusitis. Also it is safe and cost effective for long term treatments.

\section{CONCLUSION}

Betamethasone is a corticosteroid that is 300 times more potent than other corticosteroids in blocking the inflammatory process. It is safe, cost effective and can be utilized for prolong management of Allergic Rhinitis.

\section{CONFLICT OF INTEREST}

This study has no conflict of interest to declared by any author.

\section{REFERENCES}

1. Glenis S, Stephen D. Scott-Brown's Otorhinolaryngology, Head and Neck Surgery. $8^{\text {th }}$ ed. London: Hodder Arnold; 2018. 1386.

2. Dalgorf DM, Harvey RJ. Sinonasal anatomy and function. Am J Rhinol Allergy 2013; 27(Suppl-1): 3-6.

3. Barnes $\mathrm{K}$, Marsh D. The genetics and complexity of allergy and asthma. Immunol Today 1998; 19(1): 325-32.

4. Rogan C, Nicholas S. Oxford Handbook of ENT and Head and Neck Surgery. $3^{\text {rd }}$ ed. London: Oxford University Press; 2010. 164-65.

5. Gross GN. What are the primary clinical symptoms of rhinitis and what causes them? Immunol Allergy Clin 2011;
31(3): 469-80.

6. JL-Glenis KS, Valerie. Investigative Rhinology. $1^{\text {st }}$ Ed. London: Taylor \& Frances; 2004. 57.

7. Martyn L, Barnes, Quentin G. Logan Turner's diseases of Nose Throat and Ear, Head and Neck Surgery. 11 $1^{\text {th }}$ ed. Abingdon: Taylor and Francis; 2016. 73-74.

8. Wallace DV, Dykewicz MS, Bernstein DI, Blessing-Moore J, Cox L, Khan DA, et al. The diagnosis and management of rhinitis: an updated practice parameter. J Allergy Clin Immunol 2008; 122(Suppl-2): 84-90.

9. Bousquet J, Van Cauwenberge P, Khaltaev N. Allergic rhinitis and its impact on asthma. J Allergy Clin Immunol 2001; 108 (Suppl-5): 147-59.

10. Avila, P. Epidemiology of chronic rhinosinusitis. J Eur Acad Allergy Clin Immunol 2015; 119(1): 307-08.

11. Hoyte FC, Katial RK. Antihistamine therapy in allergic rhinitis. Allergy Clin Immunol 2011; 31(3): 509-43.

12. Nasser M, Fedorowicz Z. Antihistamines used in addition to topical nasal steroids for intermittent and persistent allergic rhinitis in children. Cochrane Database Sys Rev 2010; 7(7): 6989.

13. Kaliner MA, Berger WE, Ratner PH, Siegel CJ. The efficacy of intranasal antihistamines in the treatment of allergic rhinitis. Ann Allergy Asthma Immunol 2011; 106(Suppl-2): 6-11.

14. Pujols, L, López-C, Roca-F. Topical and systemic corticosteroids in chronic rhinosinusitis. Global atlas of allergic rhinitis and chronic rhinosinusitis. Eur Academy Aller Clin Immunol 2015; 346-49.

15. Dykewicz MS, Hamilos DL. Rhinitis and sinusitis. J Allergy Clin Immunol 2010; 125 (Suppl-2): 103-15.

16. Bousquet J, Lund VJ, van Cauwenberge P, Bremard-Oury C, Mounedji N, Stevens MT, et al. Implementation of guidelines for seasonal allergic rhinitis: a randomized controlled trial. J Allergy 2003; 58(1): 733-41.

17. Ciprandi G, Cirillo I, Vizzaccaro A, Tosca M, Passalacqua G, Pallestrini E, Canonica GW. Seasonal and perennial allergic rhinitis: is this classification adherent to real life? J Allergy 2005; 60(1): 882-87.

18. Van Hoecke H, Vastesaeger N, Dewulf L, Sys L, van Cauwenberge $\mathrm{P}$. Classification and management of allergic rhinitis patients in general practice during pollen season. J Allergy 2006; 61(2): 705-11.

19. Stahn C, Löwenberg M, Hommes D, Buttgereit F. Molecular mechanisms of glucocorticoid action and selective glucocorticoid receptor agonists. Mol Cell Endocrinol 2007; 275(1): 71-78.

20. Jaffery SD, David KW. Treatment options for chronic rhinosinusitis. Proc Am Thorac Soc 2011; 8(1): 132-40.

21. Jonathan B. Effect of intranasal betamethasone-17-valerate on allergic rhinitis and adrenal function. J Allergy 1969; 44(2): 77-81.

22. Edwards TB. Effectiveness and safety of beclomethasone dipropionate, an intranasal corticosteroid, in the treatment of patients with allergic rhinitis. Pubmed 1995; 17(6): 1032-41.

23. Morrow B, Storey G, Jackson F. Beclomethasone dipropionate aerosol in treatment of perennial and seasonal rhinitis. A review of five years' experience. Br J Pharmacol 1977; 4(Suppl-3): 283-86. 